\title{
Live-cell high resolution magic angle spinning magnetic resonance spectroscopy for in vivo analysis of Pseudomonas aeruginosa metabolomics
}

\author{
VALERIA RIGHI $^{1,2,4}$, CATERINA CONSTANTINOU ${ }^{1,2}$, MEENU KESARWANI $^{3}$, \\ LAURENCE G. RAHME ${ }^{3}$ and ARIA A. TZIKA ${ }^{1,2}$
}

\begin{abstract}
${ }^{1}$ Nuclear Magnetic Resonance Surgical Laboratory, Department of Surgery, Division of Burns, Massachusetts General Hospital and Shriners Burns Institute, Harvard Medical School; ${ }^{2}$ Athinoula A. Martinos Center for Biomedical Imaging, Department of Radiology, Massachusetts General Hospital, Harvard Medical School; ${ }^{3}$ Molecular Surgery Laboratory,

Department of Surgery, Division of Burns, Massachusetts General Hospital and Shriners Burns Institute, Harvard Medical School, Boston, MA 02114, USA; ${ }^{4}$ Department for Life Quality, University of Bologna, Rimini 47921, Italy
\end{abstract}

Received April 24, 2013; Accepted July 03, 2013

DOI: $10.3892 /$ br.2013.148

\begin{abstract}
Pseudomonas aeruginosa (PA) is a pathogenic gram-negative bacterium that is widespread in nature, inhabiting soil, water, plants and animals. PA is a prevalent cause of deleterious human infections, particularly in patients whose host defense mechanisms have been compromised. Metabolomics is an important tool used to study host-pathogen interactions and to identify novel therapeutic targets and corresponding compounds. The aim of the present study was to report the metabolic profile of live PA bacteria using in vivo high-resolution magic angle spinning (HRMAS) nuclear magnetic resonance spectroscopy (NMR), in combination with 1- and 2-dimensional HRMAS NMR. This methodology provides a new and powerful technique to rapidly interrogate the metabolome of intact bacterial cells and has several advantages over traditional techniques that identify metabolome components from disrupted cells. Furthermore, application of multidimensional HRMAS NMR, in combination with the novel technique total through-Bond
\end{abstract}

Correspondence to: Dr Aria A. Tzika, Nuclear Magnetic Resonance Surgical Laboratory, Department of Surgery, Massachusetts General Hospital and Harvard Medical School, 51 Blossom Street, Room 261, Boston, MA 02114, USA

E-mail: atzika@hms.harvard.edu

Abbreviations: CF, cystic fibrosis; CPMG, Carr-Purcell-MeiboomGill; HRMAS, high resolution magic angle spinning; LPS, lipopolysaccharides; NAG, N-acetyl glucosamine; NAM, N-acetyl muramic acid; OTCase, ornithine carbamoyltransferase; NMR, nuclear magnetic resonance; 1D, one dimensional; PA, Pseudomonas aeruginosa; TOBSY, total through bond correlation spectroscopy; 2D, two-dimensional; TSP, trimethylsilyl propionic-2,2,3,3- $\mathrm{d}_{4}$ acid

Key words: nuclear magnetic resonance, high resolution magic angle spinning, total through bond correlation spectroscopy, total correlation spectroscopy, Pseudomonas aeruginosa correlation Spectroscopy (TOBSY), is a promising approach that may be used to obtain in vivo metabolomics information from intact live bacterial cells and can mediate such analyses in a short period of time. Moreover, HRMAS ${ }^{1} \mathrm{H}$ NMR enables the investigation of the associations between metabolites and cell processes. In the present study, we detected and quantified several informative metabolic molecules in live PA cells, including $\mathrm{N}$-acetyl, betaine, citrulline, alanine and glycine, which are important in peptidoglycan synthesis. The results provided a complete metabolic profile of PA for future studies of PA clinical isolates and mutants. In addition, this in vivo NMR biomedical approach might have clinical utility and should prove useful in gene function validation, the study of pathogenetic mechanisms, the classification of microbial strains into functional/clinical groups, the testing of anti-bacterial agents and the determination of metabolic profiles of bacterial mutants.

\section{Introduction}

Pseudomonas aeruginosa (PA) is a ubiquitous Gram-negative bacterium that inhabits a wide array of natural environments. This bacterium is of significant clinical interest as it is a multi-antibiotic-resistant human pathogen associated with hospital-acquired infections $(1,2)$ and a major cause of morbidity and mortality in cystic fibrosis (CF) patients. It commonly colonizes the lower respiratory and gastrointestinal tracts and the mucosa and skin of hospital patients. The establishment of chronic PA respiratory infections requires a complex adaptive process that mediates essential physiological changes that allow bacterial cells to survive and persist in the host environment. Bacteria secrete small molecules that act as specific signals to positively regulate specialized processes (3), including the production of virulence factors that mediate pathogenic infection, host colonization and the promotion of interspecies microbial interactions (4).

Bacterial cell walls are complex, consisting of integrated macromolecules including carbohydrates, lipids and proteins (5). The structure and synthesis of these cell walls is 
unique, with many of the components found nowhere else in nature. Current understanding of bacterial cell wall structures is based on data derived from the destructive analyses of its individual components, and as such, this in vitro data may not accurately reflect the native structural and conformational information. An alternative approach to such analyses is the non-targeted profiling of the physiological state of bacterial cells, such as metabolomic profiling.

Metabolomics is the comprehensive determination of the low molecular-weight metabolite complement within a biological sample. As metabolites are below gene transcription and enzyme activities, the methodology of metabolomics has the potential to provide a more accurate image of the actual physiological state of a cell or cells vs. transcriptome and proteome profiling (6).

To this end, metabolomics has been used to study the response of bacteria to different physiological states and stressors (7-9) and nuclear magnetic resonance spectroscopy (NMR) has been employed to profile microbial species for differentiation and classification, including in vivo profiles of yeast strains and of marine unicellular algae via magic-angle-spinning $(10,11)$.

Cell high-resolution magic angle spinning (HRMAS) NMR spectroscopy can distinguish detailed structures present in bacteria $(12,13)$. Moreover, multidimensional HRMAS NMR is a powerful tool for the in vivo analysis of live bacterial cells (14). HRMAS is a novel non-destructive methodology that substantially improves spectral line widths to allow high-resolution spectra to be obtained from intact cells, cell tissue cultures $(15,16)$ and unprocessed tissues (17-19). HRMAS ${ }^{1} \mathrm{H}$ NMR has also enabled the investigation of relationships between metabolites and cell processes (20), as observed in a recent NMR study which reported on bacteria and PA in extracted cells (21). To avoid chemical modifications by the extraction/purification of metabolites and to mantain cell integrity, the HRMAS NMR methodology was applied to live PA to characterize and quantify the metabolic profile of these cells and their surface structures. We also focused on specific metabolites that are likely involved in PA-mediated host inflammation.

\section{Materials and methods}

Cell samples. A Rif-resistant derivative of the human clinical PA isolate UCBPP-PA14 (PA14) was used together with isogenic PA14 mutants. Bacteria were grown at $37^{\circ} \mathrm{C}$ in Luria-Bertani (LB) broth, or on LB agar plates, containing appropriate antibiotics and specific compounds, as required. Overnight PA14 cultures, grown in LB, were diluted in fresh media in triplicate. Then, $10 \mathrm{ml}$ of culture, optical density

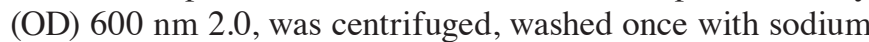
phosphate buffer and subjected to NMR.

Sample preparation and HRMAS experiments. Bacteria samples (50 and $40 \mu \mathrm{l}$ ) were introduced into the zirconia rotor (OD $4 \mathrm{~mm}$ ) and $10 \mu \mathrm{l} \mathrm{D}_{2} \mathrm{O}$ (deuterium lock reference) containing $10 \mathrm{mM}$ trimethylsilyl propionic-2,2,3,3- $\mathrm{d}_{4}$ acid (TSP), $\left(\mathrm{M}_{\mathrm{w}}=172, \delta=0 \mathrm{ppm}\right.$, external chemical shift reference) was added to the rotor with the sample plus $10 \mu 1 \mathrm{TSP} / \mathrm{D}_{2} \mathrm{O}$ solution $(50 \mathrm{mM}) .{ }^{1} \mathrm{H}$ HRMAS NMR experiments were performed on a Bruker BioSpin Avance NMR spectrometer
(600.13 MHz) using a $4 \mathrm{~mm}$ triple resonance $\left({ }^{1} \mathrm{H},{ }^{13} \mathrm{C},{ }^{2} \mathrm{H}\right)$ HRMAS probe (Bruker, Billerica, MA, USA). The temperature was controlled at $4^{\circ} \mathrm{C}$ by a BTO-2000 cooling unit in combination with a MAS pneumatic unit (Bruker).

Samples were spun at $3,000 \mathrm{~Hz}$ and two different types of one-dimensional (1D) proton spectra were obtained using a water-suppressed spin-echo Carr-Purcell-Meiboom-Gill (CPMG) pulse sequence [90-( $\tau-180-\tau)$ n-acquisition] (22). CPMG includes inter-pulse delay $(\tau=2 \pi / \omega \mathrm{r}=400 \mu \mathrm{s}) ; 256$ transients; spectral width of $7.2 \mathrm{kHz}$; 8k data points; TR=3 sec. Additional analysis of metabolites employed a novel approach combining two-dimensional (2D) solid-state, HRMAS proton $\left({ }^{1} \mathrm{H}\right) \mathrm{NMR}$, with total through-Bond Spectroscopy (TOBSY) (23), which maximizes the advantages of HRMAS and provides a robust classification strategy. Typical acquisition parameters included: $2 \mathrm{k}$ points direct dimension ( $13 \mathrm{ppm}$ spectral width), $200 \mathrm{k}$ points indirect dimension (7.5 ppm spectral width), 8 scans with 2 dummy scans, $1 \mathrm{sec}$ water pre-saturation, $2 \mathrm{sec}$ total repetition time, $45 \mathrm{msec}$ mixing time and total acquisition time $45 \mathrm{~min}$.

Quantification of metabolites. Concentrations were determined using MestReC software (Mestrelab Research, Santiago de Compostela, Spain), an automated fitting routine based on the Levenberg-Marquardt algorithm applied after manual peak selection, adjusting peak positions, intensities, line widths and the Lorentzian/Gaussian ratio, until the residual spectrum was minimized $(24,25)$. Each metabolite concentration $(\mathrm{mol} / \mathrm{kg})$ was calculated using the equation:

$$
\frac{\text { Mass TSP }(m g)}{\text { Mol weight }(T S P)} \times \frac{\text { Met peak area }}{\text { TSP peak area }} \times \frac{N_{T S P}}{N_{\text {Met }}} \times \frac{1000 \mathrm{~g} / \mathrm{kg}}{\text { Sample weight }(\mathrm{mg})}
$$

where mass TSP is constant $(0.069 \mathrm{mg})$; molecular weight of TSP=172.23 g/mol; Met., metabolite; $\mathrm{N}_{\mathrm{TSP}}$, the number of protons of TSP $\left(9^{1} \mathrm{H}\right)$ and $\mathrm{N}_{\mathrm{Met}}$, the number of protons in the respective metabolite (26).

Statistical analysis. Data were reported as means \pm standard errors. Statistical analyses were performed using the Student's $\mathrm{t}$-test. Paired two-sample test was used to determine the means. $\mathrm{P}<0.05$ was considered to indicate a statistically significant difference (Table I).

\section{Results}

The NMR metabolomic fingerprint for intact PA14 cells was determined.Fig. 1 shows a representative $1 \mathrm{D}^{1} \mathrm{H}$ CPMG HRMAS NMR spectrum obtained from live PA14 cells. The spectrum provides the direct identification and relative quantification of several metabolites, including amino acids, osmolites, phospholipids, organic acids, sugar and polyols (1, leucine; 2, isoleucine; 3 , valine; 4, lactate; 5 , alanine; 6 , lysine; 7 , bonded alanine; 8 , phospholipids; 9, glutamate; 11, glutathione; 12, aspartate; 16, phospho-choline; 17, betaine compounds; 18, glycine; 19, UMP; 22, citrulline and 24, NAD). While this NMR-based approach to cell analysis is rapid and provides significant information, it includes peaks that overlap in the 1D NMR spectra, which cannot be assigned to specific molecules. As such, 2D ${ }^{1} \mathrm{H}-{ }^{1} \mathrm{H}$ TOBSY 
Table I. ${ }^{1} \mathrm{H}$ chemical shift $(\delta, \mathrm{ppm})$ of metabolites as detected in 1- and 2-dimensional HRMAS spectra of PA14 cells.

\begin{tabular}{|c|c|c|c|c|c|c|c|c|c|}
\hline \multirow{2}{*}{ Entry } & \multirow{2}{*}{ Metabolite } & \multirow{2}{*}{$\delta{ }^{1} \mathrm{H}$} & \multirow{2}{*}{ Assignment } & \multirow{2}{*}{$\begin{array}{c}\mathrm{PA} 14 \\
(\mu \mathrm{mol} / \mathrm{g})\end{array}$} & \multirow[t]{2}{*}{ Entry } & \multirow[t]{2}{*}{ Metabolite } & \multirow[t]{2}{*}{$\delta{ }^{1} \mathrm{H}$} & \multirow[t]{2}{*}{ Assignment } & \multirow{2}{*}{$\begin{array}{c}\mathrm{PA} 14 \\
(\mu \mathrm{mol} / \mathrm{g})\end{array}$} \\
\hline & & & & & & & & & \\
\hline \multirow[t]{5}{*}{1} & \multirow[t]{5}{*}{ Leucine } & $0.95(d)$ & $\delta-\mathrm{CH}_{3}$ & \multirow[t]{5}{*}{$0.40 \pm 0.05$} & 17 & \multirow{3}{*}{$\begin{array}{l}\text { Betaine- } \\
\text { related- } \\
\text { compounds }\end{array}$} & 3.27 & $\mathrm{NCH}_{3}$ & \multirow[t]{3}{*}{$0.45 \pm 0.03$} \\
\hline & & 0.97 (d) & $\delta-\mathrm{CH}_{3}$ & & & & 3.90 & $\mathrm{NCH}_{2}$ & \\
\hline & & 1.70 & $\gamma-\mathrm{CH}$ & & & & & & \\
\hline & & 1.72 & $\beta-\mathrm{CH}_{2}$ & & 18 & Glycine & $3.56(\mathrm{~s})$ & $\mathrm{CH}_{2}$ & $0.45 \pm 0.19^{\mathrm{b}}$ \\
\hline & & 3.75 & $\alpha-\mathrm{CH}$ & & 19 & UDP & 5.98 & 1-CHrib & Related to \\
\hline \multirow[t]{3}{*}{2} & \multirow[t]{3}{*}{ Isoleucine } & $0.99(\mathrm{~d})$ & $\delta-\mathrm{CH}_{3}$ & \multirow[t]{3}{*}{$0.15 \pm 0.03$} & & & 4.38 & 2-CHrib & \multirow[t]{3}{*}{ N-Ac } \\
\hline & & 1.94 & $\beta-\mathrm{CH}_{2}$ & & & & 4.34 & 3-CHrib & \\
\hline & & 3.75 & $\alpha-\mathrm{CH}$ & & & & 4.23 & 4-CHrib & \\
\hline \multirow[t]{4}{*}{3} & \multirow[t]{4}{*}{ Valine } & $0.99(\mathrm{~d})$ & $\gamma-\mathrm{CH}_{3}$ & \multirow[t]{4}{*}{$0.21 \pm 0.02$} & & & 4.02 & 5-CHrib & \\
\hline & & 1.04 (d) & $\gamma-\mathrm{CH}_{3}$ & & & & 5.97 & 4-CHur & \\
\hline & & 2.25 & $\beta-\mathrm{CH}$ & & & & $8.11(d)$ & 5-CHur & \\
\hline & & 3.61 & $\alpha-\mathrm{CH}$ & & 20 & Uracil & 5.80 & 5-CHur & Traces \\
\hline \multirow[t]{2}{*}{4} & \multirow[t]{2}{*}{ Lactate } & 1.33 (d) & $\mathrm{CH}_{3}$ & \multirow[t]{2}{*}{$0.10 \pm 0.02$} & & & 7.53 & 6-CHur & \\
\hline & & $4.11(q)$ & $\mathrm{CH}$ & & 21 & N-Ac- & $2.01(\mathrm{~s})$ & $\mathrm{CH}_{3}$ & $0.26 \pm 0.02$ \\
\hline 5 & Alanine & $1.48(\mathrm{~d})$ & $\beta-\mathrm{CH}_{3}$ & $0.22 \pm 0.02$ & & from PS & 2.08 & $\mathrm{CH}_{3}$ & \\
\hline & & $3.79(q)$ & $\alpha-\mathrm{CH}$ & & & & 2.33 & & \\
\hline 6 & Lysine & $3.04(\mathrm{t})$ & $\varepsilon-\mathrm{CH}_{2}$ & $0.21 \pm 0.03$ & & & 2.39 & $\mathrm{CH}_{2}$ & \\
\hline & & 1.73 & $\delta-\mathrm{CH}_{2}$ & & & & 4.32 & $\mathrm{CH}_{2}$ & \\
\hline & & 1.48 & $\gamma-\mathrm{CH}_{2}$ & & & & 4.41 & $\mathrm{CH}_{2}$ & \\
\hline & & 1.91 & $\beta-\mathrm{CH}_{2}$ & & & & 5.44 & $\mathrm{CH}_{2}$ & \\
\hline & & $3.79(\mathrm{t})$ & $\alpha-\mathrm{CH}$ & & 22 & Citrulline & 1.54 & $\beta-\mathrm{CH}_{2}$ & $0.15 \pm 0.01$ \\
\hline 7 & Bonded alanine & 1.41 & $\beta-\mathrm{CH}_{2}$ & nd & & & 1.88 & $\gamma-\mathrm{CH}_{2}$ & \\
\hline & & 4.32 & $\alpha-\mathrm{CH}$ & & & & 3.15 & $\delta-\mathrm{CH}_{2}$ & \\
\hline 8 & Phospholipids & 0.89 & $\mathrm{CH}_{3}$ & Traces & & & 3.76 & $\alpha-\mathrm{CH}$ & \\
\hline & 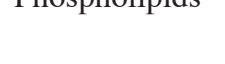 & 1.27 & $\mathrm{CH}_{2}$ & Haces & 23 & Tyrosine & $3.06,3.15$ & $\beta-\mathrm{CH}_{2}$ & nd \\
\hline & & 3.27 & $\mathrm{~N}^{+}\left(\mathrm{CH}_{3}\right)_{3}$ & & & & $3.93(\mathrm{dd})$ & $\alpha-\mathrm{CH}$ & \\
\hline 9 & Glutamate & 2.35 & $\gamma-\mathrm{CH}_{2}$ & $0.16 \pm 0.04^{\mathrm{b}}$ & & & 6.88 & Hortho & \\
\hline 3 & Gutamate & $2.06,2.15$ & $\begin{array}{l}\gamma-\mathrm{CH}_{2} \\
\beta-\mathrm{CH}_{2}\end{array}$ & $0.10 \pm 0.04$ & & & 7.18 & Hmeta & \\
\hline & & $3.77(\mathrm{t})$ & $\begin{array}{l}\alpha-\Pi_{2} \\
\alpha-C H\end{array}$ & & 24 & NAD & 8.21 & N5 ring & Traces \\
\hline 10 & Glutamine & & & $0.089^{a}$ & & & 8.93 & N3 ring & \\
\hline 10 & Glutamine & $\begin{array}{l}2.48 \\
2.14\end{array}$ & $\gamma-\mathrm{CH}_{2}$ & $0.089^{a}$ & & & 9.23 & $\mathrm{~N} 2$ ring & \\
\hline & & $\begin{array}{c}2.14 \\
3.79(t)\end{array}$ & $\begin{array}{l}\beta-\mathrm{CH}_{2} \\
\alpha-\mathrm{CH}\end{array}$ & & & & 9.44 & N6 ring & \\
\hline & & $3.19(\mathrm{l})$ & $\gamma-\mathrm{CH}_{2} \mathrm{Glu}$ & & 25 & Phenylalanine & $3.11,3.28$ & $\beta-\mathrm{CH} 2$ & nd \\
\hline 11 & Glutathione & 2.55 & $\gamma-\mathrm{CH}_{2}$ Glu & Traces & & & 3.98 & $\alpha-\mathrm{CH}$ & \\
\hline & & $\begin{array}{l}2.16 \\
3.80\end{array}$ & $\beta-\mathrm{CH}_{2}$ Glu & & & & 7.33 & Hortho & \\
\hline & & 3.80 & $\alpha-\mathrm{CH}$ Glu & & & & 7.38 & Hpara & \\
\hline & & $\begin{array}{l}2.96 \\
4.57\end{array}$ & $\begin{array}{l}\beta-\mathrm{CH}_{2} \text { Cys } \\
\alpha-\mathrm{CH} \text { Cys }\end{array}$ & & & & 7.43 & Hmeta & \\
\hline
\end{tabular}

\subsection{7}

$\mathrm{CH}_{2}$ Gly

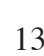

$$
\text { Cysteine }
$$$$
3.90(\mathrm{dd})
$$$$
\beta-\mathrm{CH}_{2}
$$$$
\alpha-\mathrm{CH}
$$

14 Creatine

$$
3.98
$$$$
3.04(\mathrm{~s})
$$$$
3.92(\mathrm{~s})
$$

Acetate

1.92 (s)
$\beta-\mathrm{CH}_{2}$ $\alpha-\mathrm{CH}$

$\mathrm{NCH}_{3}$

$\mathrm{CH}_{2}$

$\mathrm{CH} 3$

$\mathrm{N}\left(\mathrm{CH}_{3}\right)_{3}$ $\mathrm{NCH}_{2}$
Table I. Continued.

PA1

${ }^{a}$ one sample and btwo samples; Absolute quantification is derived from one dimensional Carr-Purcell-Meiboom-Gill; concentrations are $\mu \mathrm{mol} / \mathrm{g}$. HRMAS, high resolution magic angle spinning. NAD, niconitamide adenine dinucleotide; UDP, uridin diphosphate; d, doublet; q, quartet; t, triplet; dd, doublet of doublet; s, singlet; nd, not determined.

Traces

$0.31 \pm 0.05$

$0.04 \pm 0.01$

HRMAS was performed to complete the metabolic profiling of the PA14 cells (Fig. 2). With respect to the 1D spectra, these 2D NMR spectra allowed distinct signal discrimination, in order to identify and quantify additional metabolites including: 10, 


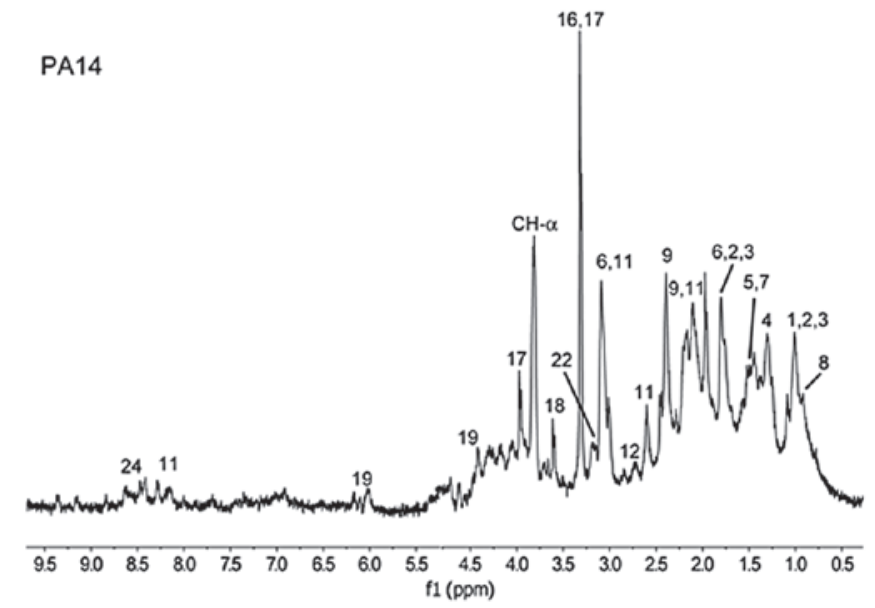

Figure 1. One-dimensional ${ }^{1} \mathrm{H}$-Carr-Purcell-Meiboom-Gill of PA14, with the different metabolites labeled: 1, leucine; 2, isoleucine; 3, valine; 4, lactate; 5 , alanine; 6 , lysine; 7 , bonded alanine; 8 , phospholipids; 9 , glutamate; 11, glutathione; 12, aspartate; 16, phospho-choline; 17, betaine compounds; 18, glycine; 19, UMP; 22, citrulline; 24, NAD.

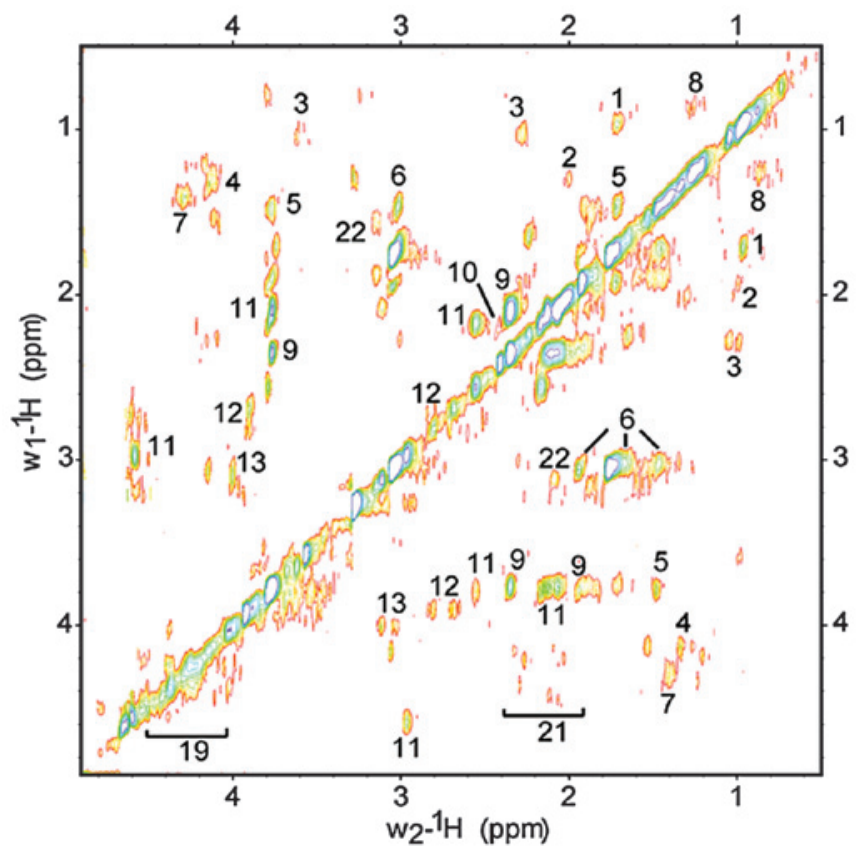

Figure 2. Representative two-dimensional ${ }^{1} \mathrm{H}$ high-resolution magic angle spinning nuclear magnetic resonance spectrum of PA14 using total through bond correlation spectroscopy. The capsular polysaccharides were detected due to their $\mathrm{N}$-acetyl signals $(21),(2.02 \div 2.33 / 4.10 \div 4.33 \mathrm{ppm})$. Glutathione (11), a major cell antioxidant, was detected with higher resolution than in the one-dimensional spectrum.

glutamine; 13, cysteine; 21, N-acetyl signal; 23, tyrosine; and 25, phenylalanine. Table I lists the 22 metabolites identified from the combined 1D and 2D spectra of PA.

\section{Discussion}

In the present study HRMAS NMR was used to provide, to the best of our knowledge, the first detailed metabolic profile of live PA bacterial cells. Several identified metabolites provide insight into the structure of the bacterial cell wall, with others giving insight into PA metabolism. Our results also identify specific metabolites that should enable future studies to better investigate the biochemical processes that occur in the host at the onset of infection and throughout pathogenesis.

Within our analysis, we detected signals corresponding to cell wall polysaccharides derived from $\mathrm{N}$-acetyl termini $(2.02 \div 2.33 / 4.10 \div 4.33 \mathrm{ppm})(27)$. This is in accordance with our previous results (28) which demonstrated that the PA cell wall contains peptidoglycans, and is a thick rigid layer composed of an overlapping lattice of the sugars, $\mathrm{N}$-acetyl glucosamine (NAG) and N-acetyl muramic acid (NAM), cross-linked by amino acid bridges (2003-2006, The Microbical World http://www.microbiologytext.com). As we also detected signals diagnostic of lipopolysaccharides (LPS), we deduce that the PA cell wall contains LPS. In addition, the 3.56 ppm peak signal, likely corresponding to glycine, is highly suggestive of cell-wall peptidoglycans and purine biosynthesis, particularly since the $3.56 \mathrm{ppm}$ peak is from $\left[{ }^{1}-\mathrm{H}\right]$ glycine metabolism in purine biosynthesis (30). Alanine, which is important in peptidoglycan biosynthesis and signaling pathways, was also detected. In peptidoglycan biosynthesis a pentapeptide is attached to each disaccharide unit at the muramic acid residue, where the final two D-alanine side chain amino acids are attached as a dipeptide $(31,32)$. This dipeptide participates in the cross-linking between peptidoglycan chains. Alanine is a necessary precursor to the dipeptide and is converted from naturally occurring L-alanine by the enzyme alanine racemase, Alr (33).

The HRMAS NMR analysis also detected betaine compounds, which are important for bacterial osmoprotection. Betaine is synthesized from betaine aldehyde via the bet $\mathrm{B}$ gene product (28). Increased betaine compounds could enhance the ability of PA to survive harsh environmental conditions in the host milieu. In particular, glycine-betaine conjugates are known osmo-protectants for many organisms, while an osmo-protective function has also been attributed to $\mathrm{N}$-acetylglutaminylglutamine amide, glutamate and trehalose in PA cells (34). The betaine aldehyde dehydrogenase (BADH) enzymes produce the osmo-protectant glycine-betaine compound, which must reach extremely high concentrations to exert its protective effect, together with enzymes participating in the catabolism of choline (35).

PA contains high levels of phospholipase C that correlate with bacterial virulence in CF lung infections (36), suggesting that choline precursors are used and metabolized during infection. Expression of the betaine aldehyde: $\mathrm{NAD}(\mathrm{P})^{+}$oxidoreductase enzyme (EC 1.2.1.8, BADH), involved in the second step of choline metabolism plus betaine aldehyde dehydrogenase are induced by choline, even when PA cells are grown in the presence of other carbon and nitrogen sources, such as glucose and ammonium (35). As such, PA-BADH is a potential target for antimicrobial agents: in addition to its involvement in choline catabolism, this enzyme may be crucial in bacterial defense against osmotic and oxidative stress, which both occur in infected tissues (37). The acid product of PA-BADH, glycine betaine, is an efficient osmo-protectant that likely acts in PA cells in the hyperosmotic environment of infected tissues (34) and BADH inhibition is likely to increase intracellular levels of betaine aldehyde, a highly toxic compound (38). To this 
end, a PA strain defective in BADH cannot grow in choline, even if glucose is present in the growth medium, due to betaine aldehyde toxicity (39). The finding that PA-BADH is expressed in the presence of other carbon compounds, such as glucose, provided that choline is present (34), supports the feasibility of using its inhibition to combat PA pathogenicity.

Citrulline was also detected as metabolite previously reported in the kinetic analysis of PA deiminase mutants (40). Ornithine carbamoyltransferase (OTCase), (EC 2.1.3.3) catalyses the carbamylation of the $\gamma$-amino group of ornithine by carbamoyl phosphate to produce citrulline and inorganic phosphate (41). This thermodynamically favored reaction further operates in arginine synthesis. PA catabolic OTCase catalyses the second reaction in the arginine deaminase pathway, which is also a component of the adenosine triphosphate (ATP) synthesis pathway under energy depletion conditions (42-44). The coupling system involving the production and deamination of ATP from ADP, and citrulline and $\mathrm{Pi}$ in the presence of carbamate, may be useful to determine the catabolic OTCase activity in the physiological direction (45). As such, increased cellular citrulline correlates with ATP synthesis. As ATP production is critical for energy metabolism and cell survival, any compound that increases citrulline may concomitantly increase energetic stamina in bacteria to improve their survival in the host and promote chronic infection.

Findings of the present HRMAS analysis identified the presence of NAD $(8.21,8.93,9.23$ and $9.44 \mathrm{ppm})$ and UDP [5.98.4.38, 4.34, 4.23, 4.02, 5.97 and 8.11(d) ppm]. These metabolites are associated with nicotinate, nicotinamide and pyrimidine metabolism, and interconnect alanine metabolism and pyrimidine metabolism. A similar relationship exists between alanine and nicotinate and nicotinamide. The use of TOBSY in HRMAS allowed the detection of all these metabolites, even when present in small amounts and hidden within other resonances. As such, this methodology provides for the detection of both aromatic compounds and aliphatic molecules, including citrulline and ornithine and arginine related-compounds. To this end, the technique is more powerful compared to the HRMAS NMR techniques previously reported and is likely to be more useful compared to other destructive high-resolution NMR techniques.

In conclusion, the combination of 1- and 2-dimensional TOBSY ${ }^{1} \mathrm{H}$ HRMAS NMR is a powerful in vivo biomedical approach to interrogate the metabolome of live bacterial cells. Multidimensional HRMAS NMR using intact cells is a promising method to obtain in vivo information of metabolomics in live bacteria and is complementary to existing chemical and biological methods. This technique may prove to be a highly useful tool in gene function validation, the study of pathogenetic mechanisms, the classification of microbial strains into functional/clinical groups, the testing of anti-bacterial agents and the interrogation of metabolic profiles of mutant strains. To this end, this technique might be applied clinically. Current limitations include spectral resolution which can be improved with compressed sensing (46) for an adiabatic TOBSY solid-state NMR pulse sequence to optimize speed of HRMAS applied to intact biopsies. Theoretical treatment, numerical simulations and experimental results on biological samples are currently ongoing.

\section{Acknowledgements}

This study was supported in part by a Shriner's Hospital for Children research grant (no. 8893) to A. Aria Tzika. This study was also supported in part by a Shriner's Hospital for Children research grant (no. 87100) to Laurence G. Rahme (Aria A. Tzika, co-investigator). We would like to thank Scott Stachel Ph.D. for editing the manuscript.

\section{References}

1. Bodey GP, Bolivar R, Fainstein V and Jadeja L: Infections caused by Pseudomonas aeruginosa. Rev Infect Dis 5: 279-313, 1983.

2. Koch C and Hoiby N: Pathogenesis of cystic fibrosis. Lancet 341: 1065-1069, 1993.

3. Bassler BL and Losick R: Bacterially speaking. Cell 125 : 237-246, 2006

4. Hoffman LR, Deziel E, D'Argenio DA, et al: Selection for Staphylococcus aureus small-colony variants due to growth in the presence of Pseudomonas aeruginosa. Proc Natl Acad Sci USA 103: 19890-19895, 2006.

5. Dmitriev B, Toukach F and Ehlers S: Towards a comprehensive view of the bacterial cell wall. Trends Microbiol 13: 569-574, 2005.

6. Griffin JL: Metabonomics: NMR spectroscopy and pattern recognition analysis of body fluids and tissues for characterisation of xenobiotic toxicity and disease diagnosis. Curr Opin Chem Biol 7: 648-654, 2003.

7. Tweeddale H, Notley-McRobb L and Ferenci T: Assessing the effect of reactive oxygen species on Escherichia coli using a metabolome approach. Redox Rep 4: 237-241, 1999.

8. Tweeddale H, Notley-McRobb L and Ferenci T: Effect of slow growth on metabolism of Escherichia coli, as revealed by global metabolite pool ('metabolome') analysis. J Bacteriol 180: 5109-5116, 1998.

9. Liu X, Ng C and Ferenci T: Global adaptations resulting from high population densities in Escherichia coli cultures. J Bacteriol 182: 4158-4164, 2000

10. Himmelreich U, Somorjai RL, Dolenko B, et al: Rapid identification of Candida species by using nuclear magnetic resonance spectroscopy and a statistical classification strategy. Appl Environ Microbiol 69: 4566-4574, 2003.

11. Chauton MS, Optun OI, Bathen TF, Volent Z, Gribbestad IS and Johnsen G: HR MAS 1H NMR spectroscopy analysis of marine microalgal whole cells. Mar Ecol Prog Ser 256: 57-62, 2003.

12. Gudlavalleti SK, Szymanski CM, Jarrell HC and Stephens DS: In vivo determination of Neisseria meningitidis serogroup A capsular polysaccharide by whole cell high-resolution magic angle spinning NMR spectroscopy. Carbohydr Res 341: 557-562, 2006.

13. Szymanski CM, Michael FS, Jarrell HC, et al: Detection of conserved N-linked glycans and phase-variable lipooligosaccharides and capsules from campylobacter cells by mass spectrometry and high resolution magic angle spinning NMR spectroscopy. J Biol Chem 278: 24509-24520, 2003.

14. Piotto M, Elbayed K, Wieruszeski JM and Lippens G: Practical aspects of shimming a high resolution magic angle spinning probe. J Magn Reson 173: 84-89, 2005.

15. Weybright P, Millis K, Campbell N, Cory DG and Singer S: Gradient, high-resolution, magic angle spinning $1 \mathrm{H}$ nuclear magnetic resonance spectroscopy of intact cells. Magn Reson Med 39: 337-345, 1998.

16. Blankenberg FG, Storrs RW, Naumovski L, Goralski T and Spielman D: Detection of apoptotic cell death by proton nuclear magnetic resonance spectroscopy. Blood 87: 1951-1956, 1996.

17. Cheng LL, Ma MJ, Becerra L, et al: Quantitative neuropathology by high resolution magic angle spinning proton magnetic resonance spectroscopy. Proc Natl Acad Sci USA 94: 6408-6413, 1997.

18. Cheng LL, Newell K, Mallory AE, Hyman BT and Gonzalez RG: Quantification of neurons in Alzheimer and control brains with ex vivo high resolution magic angle spinning proton magnetic resonance spectroscopy and stereology. Magn Reson Imaging 20: 527-533, 2002.

19. Millis KK, Maas WE, Cory DG and Singer S: Gradient, high-resolution, magic-angle spinning nuclear magnetic resonance spectroscopy of human adipocyte tissue. Magn Reson Med 38: 399-403, 1997. 
20. Righi V, Apidianakis Y, Mintzopoulos D, Astrakas L, Rahme LG and Tzika AA: In vivo high-resolution magic angle spinning magnetic resonance spectroscopy of Drosophila melanogaster at $14.1 \mathrm{~T}$ shows trauma in aging and in innate immune-deficiency is linked to reduced insulin signaling. Int J Mol Med 26: 175-184, 2010.

21. Fitzsimmons LF, Hampel KJ and Wargo MJ: Cellular choline and glycine betaine pools impact osmoprotection and phospholipase C production in Pseudomonas aeruginosa. J Bacteriol 194: 4718-4726, 2012

22. Meiboom S and Gill D: Modified spin-echo method for measuring nuclear relaxation times. Rev Sci Instrum 29: 688-691, 1958.

23. Andronesi OC, Mintzopoulos D, Struppe J, Black PM and Tzika AA: Solid-state NMR adiabatic TOBSY sequences provide enhanced sensitivity for multidimensional high-resolution magic-angle-spinning 1H MR spectroscopy. J Magn Reson 193: 251-258, 2008

24. Levenberg K: A method for the solution of certain non-linear problems in least squares. Q Appl Math 2: 164-168, 1944.

25. Swanson MG, Zektzer AS, Tabatabai ZL, et al: Quantitative analysis of prostate metabolites using 1H HR-MAS spectroscopy. Magn Reson Med 55: 1257-1264, 2006.

26. Gudlavalleti SK, Datta AK, Tzeng YL, Noble C, Carlson RW and Stephens DS: The Neisseria meningitidis serogroup A capsular polysaccharide O-3 and O-4 acetyltransferase. J Biol Chem 279: 42765-42773, 2004.

27. Kim SJ, Cegelski L, Preobrazhenskaya M and Schaefer J: Structures of Staphylococcus aureus cell-wall complexes with vancomycin, eremomycin, and chloroeremomycin derivatives by $13 \mathrm{C}\{19 \mathrm{~F}\}$ and $15 \mathrm{~N}\{19 \mathrm{~F}\}$ rotational-echo double resonance Biochemistry 45: 5235-5250, 2006.

28. van Heijenoort J: Recent advances in the formation of the bacterial peptidoglycan monomer unit. Nat Prod Rep 18: 503-519, 2001.

29. Scheffers DJ and Pinho MG: Bacterial cell wall synthesis: new insights from localization studies. Microbiol Mol Biol Rev 69: 585-607, 2005

30. Denessiouk KA, Denesyuk AI, Lehtonen JV, Korpela T and Johnson MS: Common structural elements in the architecture of the cofactor-binding domains in unrelated families of pyridoxal phosphate-dependent enzymes. Proteins 35: 250-261, 1999.

31. Lesic B, Lepine F, Deziel E, et al: Inhibitors of pathogen intercellular signals as selective anti-infective compounds. PLoS Pathog 3: 1229-1239, 2007.

32. D'Souza-Ault MR, Smith LT and Smith GM: Roles of $\mathrm{N}$-acetylglutaminylglutamine amide and glycine betaine in adaptation of Pseudomonas aeruginosa to osmotic stress. Appl Environ Microbiol 59: 473-478, 1993
33. Munoz-Clares RA, Diaz-Sanchez AG, Gonzalez-Segura L and Montiel C: Kinetic and structural features of betaine aldehyde dehydrogenases: mechanistic and regulatory implications. Arch Biochem Biophys 493: 71-81, 2010.

34. Ostroff RM, Vasil AI and Vasil ML: Molecular comparison of a nonhemolytic and a hemolytic phospholipase C from Pseudomonas aeruginosa. J Bacteriol 172: 5915-5923, 1990.

35. Kilbourn JP: Bacterial content and ionic composition of sputum in cystic fibrosis. Lancet 1: 334, 1978.

36. Rathinasabapathi B, McCue KF, Gage DA and Hanson AD: Metabolic engineering of glycine betaine synthesis: plant betaine aldehyde dehydrogenases lacking typical transit peptides are targeted to tobacco chloroplasts where they confer betaine aldehyde resistance. Planta 193: 155-162, 1994.

37. Sage AE, Vasil AI and Vasil ML: Molecular characterization of mutants affected in the osmoprotectant-dependent induction of phospholipase C in Pseudomonas aeruginosa PAO1. Mol Microbiol 23: 43-56, 1997.

38. Lu X, Li L, Wu R, et al: Kinetic analysis of Pseudomonas aeruginosa arginine deiminase mutants and alternate substrates provides insight into structural determinants of function. Biochemistry 45: 1162-1172, 2006.

39. Sainz G, Tricot C, Foray MF, Marion D, Dideberg O and Stalon V: Kinetic studies of allosteric catabolic ornithine carbamoyltransferase from Pseudomonas aeruginosa. Eur J Biochem 251: 528-533, 1998.

40. Mercenier A, Simon JP, Vander Wauven C, Haas D and Stalon V: Regulation of enzyme synthesis in the arginine deiminase pathway of Pseudomonas aeruginosa. J Bacteriol 144: 159-163, 1980.

41. Stalon V and Mercenier A: L-arginine utilization by Pseudomonas species. J Gen Microbiol 130: 69-76, 1984.

42. Vander Wauven C, Pierard A, Kley-Raymann M and Haas D: Pseudomonas aeruginosa mutants affected in anaerobic growth on arginine: evidence for a four-gene cluster encoding the arginine deiminase pathway. J Bacteriol 160: 928-934, 1984.

43. Ramos F, Stalon V, Pierard A and Wiame JM: The specialization of the two ornithine carbamoyltransferases of Pseudomonas. Biochim Biophys Acta 139: 98-106, 1967.

44. Tsao J and Kozerke S: MRI temporal acceleration techniques. J Magn Reson Imaging 36: 543-560, 2012. 